\title{
Reflexión sobre la educación y contabilidad
}

\author{
Reflection on education and accounting \\ Reflexão sobre educação e contabilidade
}

\section{ARTÍCULO ORIGINAL}

Rosario Melchora Cavero Muñante

rosario.cavero@,unica.edu.pe

https://orcid.org/0000-0002-1008-7504

Investigador Independiente, Lima - Perú

\section{Cesar Maycoll Ramos Orbegoso \\ cesarramosorbegoso@gmail.com}

https://orcid.org/0000-0002-9116-3440

Investigador Independiente, Lima - Perú

Recibido 05 de Febrero 2021 | Arbitrado y aceptado 19 de Abril 2021 | Publicado en 28 Julio 2021

\section{RESUMEN}

El presente articulo pretende realizar una meditación sobre las dinámicas de la enseñanza en el campo de la contabilidad, realizando hincapié en los inconvenientes primordiales de la educación y como las cuestiones se resuelven en el campo específico de la contabilidad, la creadora cuestiona las maneras clásicos de transmisión de conocimientos, por su falta de actualización y sentido transdisciplinar.

Se usó el término de competencia para detectar el grupo de competencias que los contadores del mundo contemporáneo necesitan, se expone tambien la necesidad de que los programas de formación profesional evolucionen más allá del saber hacer, y posibiliten novedosas herramientas y habilidades a los futuros expertos.

Palabras Claves: Educación contable; Formación por Competencias; Globalización; Capacidades

Profesionales; Docencia

\section{ABSTRACT}

This article aims to carry out a meditation on the dynamics of teaching in the field of accounting, emphasizing the main drawbacks of education and how questions are resolved in the specific field of accounting, the creator questions the classic ways of transmission of knowledge, due to its lack of updating and transdisciplinary sense.

The term of competence was used to detect the group of competencies that accountants in the contemporary world need, it also exposes the need for professional training programs to evolve beyond know-how, and to enable new tools and skills to future experts.

Keywords: Accounting education; Training by Competences; Globalization; Professional Capabilities; Teaching

\section{RESUMO}

Este artigo tem como objetivo realizar uma meditação sobre a dinâmica do ensino na área da Contabilidade, ressaltando os principais percalços da educação e como se resolvem as questões no campo específico da Contabilidade, o criador questiona as formas clássicas de transmissão do conhecimento, em razão de sua falta de atualização e sentido transdisciplinar.

O termo competência foi utilizado para detectar $o$ conjunto de competências de que os contadores no mundo contemporâneo precisam, também expõe a necessidade de os programas de formação profissional evoluírem para além do know-how e possibilitarem novas ferramentas e aptidões aos futuros especialistas.

Palavras-chave: Educação contábil; Treinamento por Competências; Globalização; Capacidades Profissionais; Ensino 


\section{Introduccion}

Para empezar, se desea retomar un asunto que se presentaba previamente, y es el asunto de las competencias. Hay un escrito bastante hermoso que desarrolló el instructor Luis Enrique Orozco (Orozco, 2016) en la Universidad de los Andes y titulado Enfoque de competencias en temas de estructuras curriculares, que no sólo está creado para el asunto de contabilidad como campo disciplinario específico, sino que realmente es una meditación universal de lo cual significan las competencias en enseñanza preeminente. Fundamentalmente, lo cual Orozco dice es que debemos ser bastante conscientes de que el término de competencia no precisamente es un criterio académico, sino que realmente es un criterio que tomamos prestado de todo el mundo laboral. Todo lo cual hacemos en competencias es intentar de producir espacios donde copiamos lo que sucede en el planeta gremial, aquello es una competencia.

Posteriormente en su escrito habla de los elementos de la competencia y apunta los próximos 3 elementos:

- La comprensión de unos fundamentos conceptuales. Para ser competente, yo debo tener un campo disciplinario, sin embargo una vez que se está hablando de enseñanza preeminente, se necesita indicar hasta dónde debe llegar dicha comprensión, por esa razón es fundamental indicar cuáles son los fundamentos disciplinarios en cualquier área de formación.

Hay unos estudios bastante fuertes que indican el problema de examinar las especialidades como silos. Entonces, en este lado está la contabilidad, por allá arriba está la gestión, por el otro lado está la economía, y realmente se vive en un ambiente en el cual el enfoque interdisciplinario se necesita para entender qué está detrás de los procesos. Pienso que aquello nos ayuda mucho a que nos dediquemos a la controversia sobre qué reglas debemos ejercer; sin embargo, no es solo un asunto de reglas, es de cuáles son los fundamentos conceptuales que las definen. Si sabemos los fundamentos conceptuales, frente a cualquier marco conductual, cualquier marco normativo, debemos estar en capacidad de entenderlo, pues entendemos lo cual está detrás.

- $\quad$ El desarrollo de capacidades. En este asunto es clave desarrollar capacidades en el sentido de qué sé hacer. El conocimiento hacer algo es 
primordial en cualquier disciplina, sin embargo, en la contabilidad, en los temas contables y de la profesión contable se vuelve un asunto esencial. Como todos en el auditorio (o casi todos) son contadores, entonces yo voy a permitirme mencionar algo polémico: a nosotros mismos nos formaron como contadores, y pienso que nos quedó una sensación de que uno estaba detrás de aquel gran escenario donde se tomaban las elecciones. Por cierto, mucha gente dice: "Es que usted elabora la información para que, por favor, se la pase a otros donde toman las decisiones".

El asunto de cómo se participa en el proceso de toma de elecciones no hablamos de entendimiento, no es que no sepamos ni conozcamos, es más bien un problema de capacidad para estar comunicados, destreza para laborar en grupo, destreza para lograr comprender qué es ejercer liderazgo, ejercerlo eficazmente y saber que uno además es capaz de ofrecer el paso al frente.

Mencionemos que en todo proceso de formación como contador se firngía increíble que se converse a modo de código morse: los contadores por el momento no se hablaban, había que decirles "la 141727", y no se entendía, empero aquello hacía que nadie más nos entendiera; era bastante hermoso entre nosotros mismos, empero nadie más nos entendía.

Ahí había un trabajo importante en el desarrollo de habilidades. Por último, hay un tema que llama mucho la atención, porque es un gran reto: es el temple y la templanza de la actitud frente al mundo y a su disciplina.

\section{Metodologia}

La metodología que se utilizó consta de una búsqueda de información a base de papers, revistas, análisis de aplicaciones actuales y páginas web especializadas para entender su funcionamiento, el nivel de desarrollo obtenido en la actualidad y cuáles son sus principales aplicaciones.

Además, se han empleado análisis de modelos estratégicos acordes para analizar el atractivo de las industrias en la adopción de la tecnología y así determinar a través de modelos de análisis de negocio cuáles son las industrias en que tendrá mayor incidencia. La búsqueda de la información para la revisión de literatura se hizo consultando las 
siguientes bases de datos como son, Scopus, Proquest y Google Académico para encontrar revistas del más alto nivel científico.

Asimismo, cabe mencionar que para la realización de lo mencionado se emplearon también palabras clave como Educación contable; Formación por Competencias; Globalización; Capacidades Profesionales; Docencia Cada uno de estos descriptores se combinaron entre sí durante la búsqueda utilizando los operadores boléanos "and" y "or". Además, algunos de los criterios o filtros que se utilizaron para hacer muchos más específica la búsqueda y ser más precisos con los documentos encontrados en las diferentes bases de datos consultadas fueron: que sean artículos de revistas, y la antigüedad de la publicación que no sea mayor a 5 años.

Toda la información previa relacionada a los filtros aplicados y las especificaciones sirvieron como criterios de inclusión, es decir que sean artículos publicados en revistas científicas, que no excedan los cinco años de antigüedad, que latemática guarde relación con las variables de creatividad artística y tiempos de pandemia. Se excluyeron, en tanto, todos los documentos que no respetaran lo postulado, así como aquellos que estaban incompletos o que tenían enlaces averiados.

\section{Resultados y discusión}

\subsection{La concepción sobre el tipo de sociedad}

Las propuestas curriculares permanecen, o deberían estar fundadas en una concepción sobre el tipo de sociedad para el cual están compuestos expertos. La pregunta por la sociedad imaginada ayuda a entablar marcos de congruencia entre la iniciativa curricular, su sentido pedagógico, su manifestación didáctica, y generalmente, funciona como soporte para conservar una vigilancia del contenido teleológico de la enseñanza. En varios casos algo de esta imagen se refleja en la obra de los perfiles de formación y expertos; sin embrago, no es extraño el señalamiento de que esta clase de estructuras terminan siendo utópicas o enunciaciones "de papel”.

Son varios los matices encontrados y deseamos dejar consignado el grupo de adjetivos, valores y sustantivos usados para explicar la sociedad que es pensada a partir de cada currículo de Contaduría Pública consultado: pluralista, informada, pluricultural, educada, fragmentada, cooperativa, ética, abierta, en crisis, excluyente, sustentable, integral, democrática, pacífica, igualitaria, 
librepensadora, humanista, una sociedad que debería ser comprendida más que exitosa, con inconvenientes de diferencia y ingreso a la riqueza, con valores, espiritual, compleja, en tensiones de globalidad y metrópoli, exigente, evolutiva, cambiante [...]. Si nos ponemos a ver estas descripciones, mayormente proyectan un tipo de sociedad ideal que debe ser aquella en la cual habiten los expertos contables. Ciertos actores hicieron una explicación en funcionalidad de los inconvenientes presentes en la sociedad en la cual vivimos y que deberían ser confrontados con el proceso de formación. Esto nos deja una fundamental preocupación sobre la formulación del tipo de sociedad que debería estar presente en el momento de conceptualizar o redefinir los criterios de un programa educativo, en esta situación, Contaduría Pública; parece plausible en la obra o transformación de las propuestas curriculares, detectar las descripciones que se realizan sobre el estado de hoy de la sociedad, los valores presentes, los recursos de crisis, (...), y confrontarlas con una visión teleológica de dicha iniciativa de sociedad relacionadas con las maneras de la profesión contable para colaborar en su logro. Recordemos que esta definición es fundamental pues a partir de ella se comienzan a plantear señales para la concepción pedagógico - didáctica que asume o que asiste al programa.

Ejemplificando, una universidad donde gravite una concepción de la sociedad como la que enunciamos luego, convoca cuestiones, o alertas, respecto de una formación focalizada en lo técnico, instrumental y legal: "una sociedad liberal, competitiva y que promueva la autogestión" (P.U). Por lo menos tener claridad sobre una orientación en este horizonte, previene discusiones bizantinas sobre la formación humanista, o la formación integral que precisamente promueven una iniciativa de lo social y de la sociedad a partir de otra visión.

Igualmente la obra de currículos sin clarificar la concepción de lo social, puede arrastrar formulaciones clásicos, o inclusive, operar una perspectiva automática casi constantemente producto de dinámicas regulativas y entornos económicos. Respecto de su universidad un instructor propuso: "en rigor no le asiste una concepción de sociedad, en tanto su formulación fue guiada por consideraciones de todo el mundo del trabajo, propias de la otrora sociedad industrial" (P.U). 
Esta orientación instrumental fue acusada en diversos trabajos sobre enseñanza contable; es innegable que la lógica eficientista, las dinámicas de mercado y el carácter técnico, permanecen presentes en la cosmovisión de la formación. Este caso posibilita, ejemplificando, a ciertos actores enunciar como legítimo que en su universidad "se elabora a los alumnos para saciar necesidades del mercado gremial. Sin embargo que sean empresarios, emprendedores, creadores de organización, generadores de empleo". (P.U)

\subsection{Modelo pedagógico}

Un modelo pedagógico, o lo pedagógico, responde a la pregunta por el tipo de hombre y de dama que debería formarse bajo una concepción específica social, en consonancia con dinámicas históricas y contextuales (Díaz y Quiroz, 2021). Por consiguiente la iniciativa sobre lo pedagógico es vasta y se convierte en orientación para los demás procesos como la didáctica, la evaluación y el diseño curricular.

Lo pedagógico surge como una aseveración de sentido evidente en la obra de los proyectos de formación. Sin embargo, esta categoría educativa se experiencia y por esto, más que lo enunciado, lo cual pasa como práctica maestro, como evaluación, como administración, apunta el verdadero encuadre pedagógico de un programa, o las mixturas que en él son reconocibles.

Para acercarse a una caracterización desde este tópico, la idea de modelo permite simplificar el amplio escenario de la pedagogía. Por ello es preciso advertir que un modelo recoge patrones comunes, representa en líneas gruesas, y por lo tanto no debe confundirse con la realidad misma. Sirve como referente analítico, como visor desde el cual se pueden hacer distinciones; pero es obligado reconocer mayor complejidad e indicar la dificultad para establecer los tabiques que, en la manifestación de la realidad educativa, separan un modelo de otro. Según González (2020) podrían clasificarse los modelos pedagógicos como sigue:

Modelo pedagógico tradicional: se presenta como un trayecto lineal por un conjunto de conocimientos - saberes clásicos. Busca sacar al discente de su condición de no ilustrado utilizando principios de acción como la voluntad, la disciplina y la normatividad. Está matizado por la exposición verbal de un maestro 
Rosario Melchora Cavero Muñante, Cesar Maycoll Ramos Orbegoso

transmisor de conocimientos, dictador de clases, exigente, castigador, en relación vertical, con un alumno receptivo, repetitivo y memorista. Maneja contenidos enciclopédicos, evaluación cuantitativa, con predominio del proceso de enseñanza, sin una reflexión compleja sobre el proceso de aprendizaje.

Modelo pedagógico conductista: moldea la conducta de los individuos según necesidades productivas del Estado. Funciona con base en objetivos terminales e instrumentos claros de medición de logros. Se fundamenta en procesos de estímulo - respuesta, causa - efecto, objetivo - logro. Su trayecto es lineal. Sus contenidos son enciclopédicos. Sus métodos son transmisionistas. Su evaluación es memorística y cuantitativa. Promueve enfoques racionalistas y positivistas asumiendo lo cognitivo como un proceso psico - conductual. Privilegia el proceso de enseñanza concibiendo el aprendizaje como una cuestión automática.

Modelo pedagógico desarrollista: su eje fundamental consiste en aprender haciendo. Su trayecto es no lineal entregando opciones para que el discente construya su proyecto formacional. Desarrolla habilidades de pensamiento para que las personas enfrenten el mundo real. Sus contenidos están focalizados al desarrollo científico y su lógica de construcción. El proceso de aprendizaje prima sobre el proceso de enseñanza. El docente actúa como facilitador para la estructuración de las formas de pensamiento del estudiante. La evaluación es procesual y cualitativa. La apropiación de conocimiento se logra mediante la experiencia - contacto directo con los objetos de estudio -. Promueve la reflexión y la crítica.

Modelo pedagógico social: relaciona el mundo de la universidad con el mundo de la vida. Los estudiantes desarrollan competencias en torno a necesidades sociales. El profesor es un investigador de su práctica

educativa y el aula es un taller donde se construyen soluciones. Su trayecto es no lineal. El currículo es flexible y se adapta a las condiciones contextuales. Trabaja más en función a problemas que a contenidos. Los contenidos utilizados son recreados utilizando las metodologías afianzadas por el pensamiento científico. El docente es un detonador de procesos donde la pregunta es importante. Las metodologías privilegian el trabajo en grupo y las didácticas están orientadas a provocar escenarios dialécticos. La evaluación es 
cualitativa. Vincula la investigación de forma activa en cada uno de los procesos formativos. Confronta la cultura universal con la cultura local. Logra equilibrio entre los procesos de enseñanza y aprendizaje.

En el escenario de la Contaduría Pública la primera conclusión que es posible someter a discusión es la ausencia de formación en la comprensión de lo pedagógico y su incidencia en nuestro rol como profesores o directores de programa; del mismo modo se refleja una tendencia a identificar como más cercano a la realidad de algunas universidades el modelo pedagógico tradicional y conductista:

La perspectiva dominante es la del modelo pedagógico conductista. Emergen otras propuestas aisladas desde diferentes docentes. Igualmente no es una decisión o directriz institucional el desarrollar este modelo (conductista). Más bien el modelo se adopta de facto ante la debilidad pedagógica de los docentes. (P.U)

Dado que en la actualidad el programa refleja una perspectiva tradicional, todos los recursos y actividades que giran y se integran en él, determinan el perfil del egresado: más técnico que profesional, más memorístico que propositivo. (P.U)

También podemos identificar tensiones propias que viven las universidades y los programas de Contaduría Pública en su necesidad de avanzar en la consolidación de propuestas pedagógicas un poco más "modernas":

Nuestro programa ha realizado un interesante proceso de reflexión crítica en torno a nuestra realidad y encontró que nuestro modelo pedagógico estaba orientado más hacia el hacer y que se había olvidado de múltiples aspectos tales como: flexibilidad, integralidad, interdisciplinariedad. Sin embargo, también encontramos que contábamos con grandes fortalezas. Luego de aproximadamente 5 años de trabajo que coincidían con el "despertar" de la universidad sabemos que hemos cambiado y estamos cambiando. Concebimos y venimos desarrollando avances curriculares que nos acercan al modelo pedagógico social, sin que esto quiera decir que todos nuestros docentes hayan asumido el nuevo modelo. Es un proceso que de alguna manera se ve favorecido por el relevo generacional y como lo manifesté antes por la misma dinámica de transformación de la Universidad. (P.U)

Desde el "deber" ser la propuesta curricular pretende articular elementos pedagógicos sociales, por ello pienso en ese modelo. Creo que el estado de desarrollo del programa, por sus avances y dificultades podría ubicarlo en su 
"ser" en el desarrollista con una preocupación alta por el tema de "lo social" que está en proceso de reflexión permanente. (P.U)

Aunque el modelo preponderante es el pedagógico tradicional, no puede desconocerse la variedad de prácticas pedagógicas observadas al interior del desarrollo del proceso educativo, protagonizadas por un sector docente con modalidades eclécticas y / o mixtas, que incorporan elementos de otros modelos, como son la multivariedad metodológica, epistémica y evaluativa, las consideraciones contables, el valor de la investigación como actividad esencial y estratégica, la flexibilidad y la formación para el mundo de la vida y sus permanentes tensiones. (P.U)

El modelo social es el que pretende alcanzar la universidad, pero en este momento estamos en el tradicional - conductista. (P.U)

En estos testimonios se reconoce la dificultad subyacente para acortar la brecha entre el modelo idealizado por la institución y el que realmente se manifiesta en el escenario sociológico de la formación. Esta brecha se explica por la diversidad de los actores universitarios, pero también por las tensiones que surgen cuando se desatan procesos de cambio y transformación que implican un cuestionamiento severo a ciertas tradiciones.

Justamente, también evidente en algunas respuestas ya citadas, suponer que en un programa se sigue en forma pura un determinado modelo resulta impreciso. Por ejemplo esto manifestó uno de los profesores: "Taxativamente no podría encuadrarse rígidamente el modelo pedagógico en esta clasificación. Puede ser que algunas características del modelo tradicional puedan complementarse con algunos elementos de otros modelos" (P.U). Así, es improbable que en una institución se siga a carta cabal las trazas que matizan un modelo. Pero es importante que la universidad y sus programas, se pregunten por cuál de los escenarios que han sido diferenciados por la teoría de la educación y la pedagogía, se convierte en prescripción del sentido de lo pedagógico, lógicamente como resultado del diálogo de los actores, y teniendo claridades respecto de la complejidad y diversidad que subyace a los procesos de formación.

También aparece en algunas expresiones la confusión entre pedagogía y didáctica. Una perspectiva pedagógica que por ejemplo privilegie la construcción, el diálogo, y el aprendizaje más que la enseñanza, no implica obligatoriamente la 
exclusión de clases magistrales. En ocasiones ciertas didácticas que pueden sonar chapadas a la antigua, resultan más pertinentes para desarrollar ciertos temas en los que el profesor debe exponerse para señalar rutas de comprensión de una temática. Ciertos discursos interesados en modernizar la didáctica y la forma de hacer clase, caen en el esnobismo irreflexivo que pasa muy rápido por la tensión entre objeto de formación y metodología de abordaje / enseñanza / aprendizaje. Algunas consideraciones que nos señalan estas dificultades pueden ser: "nuestro modelo educativo es lograr que el estudiante construya su propio conocimiento. No tenemos cátedra magistral. El profesor es un facilitador del proceso de aprendizaje propio del estudiante. Hacemos énfasis en el trabajo en grupo" (P.U); o también sostener que es posible hablar de tantos modelos pedagógicos como asignaturas se orienten: "el modelo que más se parece al aplicado en la asignatura de contabilidad financiera es el desarrollista. Sin embargo la evaluación aplicada no es solamente cualitativa; también hay evaluación cuantitativa; además algunos temas no están focalizados al desarrollo científico" (P.U). Esta situación permite señalar que es equivoco suponer que la reorientación de algunos procesos didácticos siempre produce cambios en la postura y proyección pedagógica; el que se desarrollen algunas innovaciones en los procesos didácticos debe estar precedido de una reflexión sobre el tipo de sociedad y hombre que debe formarse, de una reflexión sobre el contenido específico que se selecciona como campo temático y su disposición como objeto de formación (didaxis) y de las particularidades del discente que se forma.

Transitar hacia una nueva forma pedagógica implica un trabajo de reconocimiento de las características de cada programa y universidad. Una propuesta que resulte distante de las posibilidades de los agentes y de la estructura universitaria aparecerá quizá bien documentada pero no encontrará asidero en las prácticas concretas de la educación contable. En estas transformaciones el papel del docente es crucial; si el agente que soporta el rol de seducir al estudiante para el conocimiento no incorpora los presupuestos que el programa define como guía de su trabajo, no habrá otro espacio u otro agente que pueda sobrellevar tan importante tarea. Por ello resulta problemático suponer que el estudiante puede transgredir la lógica educativa que le proyecta su institución: "pero el esquema tradicional parece ser funcional y su abandono depende de la 
Rosario Melchora Cavero Muñante, Cesar Maycoll Ramos Orbegoso

concientización de los estudiantes de su propia formación (P.U). Sostenemos que el estudiante debe autonomizarse y concebir estéticamente su proyecto formativo, mas ello, sólo será posible si su institución y su profesor le proponen señales y rutas para construir su perspectiva de sí en relación con la de los demás.

También esperamos que las universidades que empezaron en su momento procesos de transformación vayan en el camino de cualificar la formación de contadores públicos y que hayan trascendido la presión derivada de procesos de registro calificado y acreditación, que ha maximizado las dinámicas de reforma en la universidad. Un ejemplo de expresiones en este sentido: "la universidad está en la construcción de un modelo pedagógico de carácter dialógico, en el que sea posible el pluralismo epistemológico sobre la base de una concepción de pensamiento sistémico - holista y Humanista.” (P.U)

En varios espacios hemos venido sosteniendo la necesidad de transitar de una dimensión menos mercantilista de la formación contable, tanto en la percepción de la educación como en la concepción que tenemos del ejercicio profesional de la Contaduría Pública, a posturas más integrales, más científicas y más transformadoras. Sin embargo la realidad nos presenta la ausencia de movimiento en el sentido esbozado. "En mi opinión se está formando un técnico contable y no un profesional crítico - analítico - propositivo.” (P.U). El currículo "está diseñado para atender las necesidades del mercado. Nuestro contador se forma con enfoque de: auditor, tributarista y contable" (P.U). Zanjar este tipo de posturas es condición para el movimiento hacia modelos pedagógicos que podemos encuadrar como desarrollistas y sociales, que privilegien otras miradas del mundo de la vida, menos fincadas en la instrucción y el conductismo.

\subsection{La educación contable como acción educativa}

Es prioritario buscar un lugar desde el cual emprender acciones para transformar algunos de los conflictos que se evidencian a partir de las expresiones de algunos actores de la educación contable en Colombia. Estos conflictos están soportados también en estudios que acusan situaciones que pueden sintetizarse en los siguientes enunciados:

- Las instituciones de educación superior emergentes y las antiguas han perdido su carácter de instituciones y más parecen organizaciones del mundo de los negocios. (López, 2018) 
Rosario Melchora Cavero Muñante, Cesar Maycoll Ramos Orbegoso

- La gestión universitaria ha estado matizada por exigencias eficientistas y requerimientos de mercado, dejando de lado el aporte en capacidades para forjar un proyecto de nación independiente. (Gracia, 2017)

- Hay una tendencia generalizada a la formación ultra-especializada y fragmentaria en educación superior. (UNESCO, 2018)

- En nuestro país la educación contable no ha sido problematizada filosóficamente. (Quijano, Gracia, Martínez, Ariza, y Rojas, 2020)

- - "El problema crucial de nuestras facultades de Contaduría Pública, estriba en que el currículo sólo se centra en el nivel técnico del saber contable, sin fundamentación teórica para el diseño, desarrollo y administración de sistemas contables y de control empresarial, por sectores económicos y a nivel privado y estatal, de acuerdo con las necesidades del desarrollo económico.” (ICFES FIDESC, 2020, p. 7)

- - "Desafortunadamente, por lo menos en Contaduría, el currículum se ha visto desde una óptica pragmática, en torno a organizar "qué" y "cómo" enseñar reduciendo problemas centrales del proceso de formación a una organización técnica.” (Barragán, 2018, p. 162)

- - "Los currículos son rígidos, inflexibles y cerrados, distribuidos por asignaturas convencionales, intensidades horarias, créditos, profesor y aula propia." (Flores, Díaz, Tobón y Agudelo, 2020, p.23)

- - "Tradicionalmente ha existido la tendencia, en los programas contables, a marginar los procesos académicos de los análisis contextuales, haciendo de la educación un fenómeno artificioso, tautológico, y muy distante de la problemática y la realidad social. Lo anterior, emerge como consecuencia de trabajar con modelos pedagógicos que privilegian lo asignatural y con ello el desarrollo de competencias cognitivas simples.” (Martínez, 2018, p. 85)

- - "La importación de estos modelos (regulativos), que se ofrecen como capacitación en los centros educativos, fortalece la incomprensión de la relación investigación y docencia, por cuanto en materia de contabilidad sólo basta transferir técnicas y tecnologías ya hechas, que al parecer invalidan, una apuesta por la búsqueda de nuevas respuestas e incluso la crítica a lo importado. Esto explica (en alguna medida) por qué en la universidad y en los programas de contaduría, el énfasis en lo investigativo aparece como novedad, cuando lo natural 
Rosario Melchora Cavero Muñante, Cesar Maycoll Ramos Orbegoso

es que la esencia de la universidad sea la investigación” (Ospina, 2018, p. 86) (subrayado añadido)

- - "Uno de los principales déficits que tienen nuestros sistemas educativos radica en la ineficiencia de los instrumentos evaluativos de los cuales se hace habitualmente uso. Más que contribuir a permitir un proceso de interacción formativa en el cual el docente califica el trabajo realizado y corrige y orienta al alumno para enmendar errores y profundizar ciertas áreas débiles, las evaluaciones terminan siendo un instrumento represivo que no ayuda a desarrollar aprendizajes." (Elizalde, 2020, p. 6)

Estas manifestaciones problemáticas atribuibles a la educación contable son síntomas visibles de una crisis más aguda: “el sentido de la educación”. Y es en la distinción de ese sentido que podríamos comprender y emprender el conjunto de intervenciones coherentes dirigidas a reformular los tópicos más relevantes de esta problemática. Dicho de otro modo, la intervención aislada de los elementos que conforman el sistema educativo, sin haber hecho un juicio sobre el sentido de la educación contable en la universidad, es un esfuerzo condenado a la infertilidad.

En esta tercera parte del texto se intenta proponer una discusión sobre ese sentido de la educación como punto central y de partida para poder pensar (en otras oportunidades) asuntos concretos como pedagogía, currículo, didáctica, evaluación, entre otros. Si asumimos la siguiente expresión como un lugar de anclaje, se hace evidente el profundo impacto que genera esta tarea: "cuando hablamos de la naturaleza de la educación en Contabilidad, estamos diseñando el futuro de nuestra disciplina" (Bedford, citado por Túa, 2021, p. 900). Por ello se reitera que no es coherente iniciar reflexiones aisladas sobre tópicos educativos, si no se ha construido un lugar común y contundente sobre el sentido de la educación contable universitaria. Quizá ese lugar, sus razones y consecuencias tengan que ver con la educación en general.

Resultan evidentes por lo menos las siguientes dos situaciones características de la educación contable actual (quizá también aplique a otras carreras universitarias):

1) está fincada en lo instrumental; supone un individuo promedio y universal, competitivo, emprendedor y calculador que siempre racionaliza su acción en función de maximizar la utilidad previsible; entiende el mercado como el escenario en el cual se resuelven sus aspiraciones y metas, por ello el acto privilegiado de desarrollo personal es el consumo. Bajo este tipo de características resulta casi imposible formar 
a ese sujeto en un proyecto identitario en el que pueda potenciar su diferencia, es decir, acceder a su distinción, básicamente porque esa educación pretende la homogenización y no la diversidad;

2) la educación contable se produce en una universidad que se ha volcado a la gestión de la calidad, optimizando recursos, rentabilizando la oferta educativa (mayores coberturas con menores inversiones), minimizando el proceder científico que implica asumir ciertos costos y ciertas lógicas de gestión y dejando de encarar la "tarea" por la verdad; una universidad que se ha convertido en una organización empresarial que tergiversa las relaciones propias de la concepción ideal y compleja del campo universitario4: La pluralidad, la verdad, la construcción de subjetividad y el acceso democrático al conocimiento y su promoción social.

En otras coordenadas, pero operando dialécticamente con estas concepciones estructurantes ya mencionadas, se presenta la tensión entre la educación como espacio para el adiestramiento, transmisora de saber, vertical, autoritaria, profundamente conductista, en la que unos sujetos ostentan la posición de poseer conocimiento y otros, desposeídos, aprenden por emulación, repetición o memorización, la doctrina impartida por sus maestros; y la educación, quizá en el otro extremo, desestimando la noción de autoridad del saber, una educación concebida para una interacción horizontal que pone en un mismo lugar a los actores (maestros y estudiantes), que privilegia lo conversacional, la "construcción de saber" en los espacios formativos, que subraya la tolerancia por la diversidad y que acentúa la diferenciación y por ende el individualismo.

Se puede interpretar apoyados en Arendt que ambos esquemas obedecen a procesos socio - históricos específicos y tienen profundas dificultades. El primero, emparentado con las formas del totalitarismo de principios del siglo XX, está "justificado" por su demanda de individuos profundamente moldeados y estandarizados para insertarse en las dinámicas burocráticas públicas y privadas de marcado centro Europeo; el segundo de reciente aplicación en el contexto estadunidense, privilegia las formas del individualismo propias del capitalismo tardío, en las que lo plural y diverso se subraya como necesidad de identificación de cada sujeto, pero sobretodo en la esfera del consumo. Con relación a este último modelo plantea Arendt (2019):

Lo que hace tan aguda la crisis educativa americana es, pues, el carácter político del país, que lucha por igualar o borrar en la medida de lo posible las diferencias entre 
jóvenes y viejos, entre personas con talento y sin talento, entre niños y adultos, y en particular, entre alumnos y profesores. Es evidente que ese proceso puede cumplirse de verdad sólo a costa de la autoridad del profesor y a expensas de los estudiantes más dotados. (p.201)

La concepción de la educación que se afianza en la forma de la autoridad (saber) del maestro ha sido suficientemente criticada por la inercia de pensamiento y acción que produce en el discente. Esta concepción se asocia con los modelos pedagógicos memorísticos y conductistas declarados obsoletos por la teoría educativa actual. Sin embargo, las propuestas que surgen como respuesta a esta crítica, muchas de ellas cimentadas en el paradigma construccionista, exacerban la noción de que la participación y opinión del estudiante y su interacción es la base del proceso educativo. Esa igualación de la que habla Arendt entre maestros y estudiantes que paradójicamente se centra en la importancia de la diferencia y la pluralidad, en la validez de cada percepción, y en el relativismo absoluto en la construcción de saber, plantea importantes problemas para comprender pautas de comportamiento social. "Este individualismo debilita el sentido de la comunidad y de la tradición, y acaba por reducir la vida humana a opciones concretas aquí y ahora. El mundo aparece ante las personas afectadas por dicho individualismo como un campo de oportunidades para sus deseos particulares. Parece no haber límites para esta actividad desiderativa". (Barone y Mella, 2017, p. 199) Estas manifestaciones del fenómeno educativo se hacen presentes en el contexto de la educación contable, máxime en tiempos de reformas curriculares, procesos de registro y acreditación, rediseño educativo, construcción de proyectos educativos de programa, entre otros; las situaciones pueden ser sintetizadas como: educación contable para la racionalidad instrumental, instrumentalización de la educación contable, modelos educativos conductistas y modelos educativos que profundizan el individualismo muy característico de la postmodernidad o contemporaneidad. Estos escenarios afectan el sentido de la educación. Y entonces, ¿cuál podría ser un sentido de la educación que sirviera de soporte al proceso educativo, que impacte la educación contable?

En la perspectiva de la relación entre profesor y estudiante es prudente comprender que el profesor sobrelleva una responsabilidad compleja. Y esa responsabilidad implica que en él reside un principio de autoridad - poder, en tanto debe hacer todos los esfuerzos para que su papel en el acto educativo se cumpla. No se trata de autoritarismo, ni del poder que aparece como violencia, o como ausencia de posibilidades de diálogo o 
nuevos consensos. Es el poder de "mostrar" un saber, una experiencia para convocar un proyecto formativo en su estudiante. A este respecto Foucault señala:

el problema no es entonces, intentar disolverlas (las relaciones de poder propias del acto educativo) en la utopía de una comunicación perfectamente transparente, sino de darse las reglas de derecho, las técnicas de gestión y también la moral, el ethos, la práctica de sí que permitirán, en esos juegos de poder, jugar con el mínimo posible de dominación. [...] Yo no veo adónde está el mal en la práctica de alguien que, en un juego de verdad dado, sabiendo más que otro, le dice lo que debe hacer, le enseña, le transmite un saber, le comunica técnicas; el problema es más saber cómo se va a evitar en esas prácticas donde el poder no puede dejar de jugar, y donde no es malo en sí- los efectos de dominación que harán que un niño sea sometido a la autoridad arbitraria e inútil de un instructor, un estudiante bajo el dominio de un profesor autoritario, etc. Creo que hay que postular este problema en términos de reglas de derecho, de técnicas racionales de gobierno y de ethos, de práctica de sí y la libertad. (2017, p. 277).

Es evidente que el estudiante, en este caso de Contaduría Pública, necesita maestros, personas que se comprometan en la configuración de experiencias para la construcción de sentido sobre el saber, las técnicas, los contextos, las causas y consecuencias de una modalidad - campo del conocimiento. Y esta experiencia debe pasar por facilitar el dominio (competencia) pero también la identificación de ese dominio en relación con la subjetividad del estudiante. Por ello es apenas lógico que en ese "mostrar" del profesor, se comprenda la red de sentido implicada para poder hacer una distinción de la cultura de la disciplina o saber objeto de estudio; para esto se requiere de estudiantes dispuestos a escuchar (que no quiere decir pasivos) para luego dar paso, dialógicamente, a la deconstrucción del saber objeto, en la actividad formativa. El diálogo tendrá efecto formativo, solo si hay un lugar del cual tomar los elementos de la discusión; y esto no quiere decir que se encuentra ungido de "verdad" lo que propone el profesor. Quiere decir que hay un lugar, una perspectiva, desde la cual cargar de sentido la experiencia vital; tanto el profesor como el estudiante se ven expuestos a nuevas comprensiones. Y ese es el sentido de la relación profesor - estudiante en el acto educativo: detonar una comprensión.

¿Y sobre qué se opera esta relación? ¿A qué se compromete? En un escenario como el de la Contaduría Pública parece sencillo señalar que la materia prima está compuesta por un conjunto de conceptos, herramientas, técnicas y metodologías de la contabilidad, la economía, la administración, el derecho, entre otras, que habilitan al estudiante, le 
hacen competente, para desempeñar sus campos de acción; para desarrollar su ejercicio profesional. Por supuesto, las características de los desempeños están determinadas por las necesidades de las organizaciones económicas, y por la dinámica del mercado de servicios profesionales. Y es justo decir que ese mercado se sustenta o sostiene solo con habilidades técnicas y procedimentales del contador público. Los contenidos y las características de los espacios formativos son, en este sentido, concebidos en función de esta reducida comprensión de la relación universidad y contexto. No es exagerado plantear que si ese es el telos de la educación contable, tal entelequia no requiere la universidad como lugar para su logro; al menos no, la universidad en su sentido más riguroso.

La educación contable universitaria debe entonces acercarse responsablemente a cumplir su tarea, que supera el escenario de preparar contadores hábiles en la aplicación de la racionalidad instrumental. Debe superar el sentido de la educación para el trabajo. Para Arendt existen tres actividades fundamentales que explican las formas como vive el ser humano: labor, trabajo y acción. La labor se asemeja al normal desarrollo de las necesidades corporales caracterizadas por lo cíclico y la fugacidad (Barone y Mella, 2017); piénsese por ejemplo en la alimentación, o el dormir. El trabajo se manifiesta como una actividad artificial, que produce una obra que puede tener condiciones de perennidad y por lo tanto se hace sin el cuestionamiento de la relación con quien la produce. "Al profesor y al alumno se les exigen obras o trabajos que sirven de base para la interacción humana que es la educación. Sin embargo, la exigencia del trabajo de producir una obra corre el riesgo de la reificación, de la instrumentalización, y la mercantilización" (Barone y Mella, 2017, p. 201). Este mundo de la fabricación (Bárcena y Mélich, 2020) gravita en función de apuestas utilitarias; cualquier actividad debe reportar un rédito medible en términos de eficacia. "El mundo de la fabricación no tolera la pregunta por la "razón de la utilidad". No se puede cuestionar su valor de uso. En el universo del homo faber, todo tiene que servir para algo, todo debe ser útil, es decir, debe presentarse como instrumento para hacer algo más” (p. 75). En este mundo del trabajo / fabricación se forman funcionarios, sujetos que cumplen funciones en una burocracia específica; (...) "el objeto de este proceso es la creación de nuevos y devotos funcionarios que se integren dentro del tejido social. Este parece ser el gran objetivo de la educación - fabricación”. (p.78). En Contaduría Pública no cabe duda de que hoy por hoy se están formando "funcionarios". 
En este sentido para un análisis completo de la educación, la condición artificiosa (trabajo / fabricación) no es la más adecuada, máxime si resultan ciertos y diáfanos los compromisos que los programas de Contaduría Pública muy elocuentemente exponen en sus documentos educativos y en las publicidades que utilizan para atraer nuevos estudiantes: formación crítica, formación en innovación, formación integral, formación del ser, formación ética, formación responsable, entre otros muchos. Si bien la educación contable debe garantizar el logro de competencias laborales, tal encargo no puede estar desprovisto de la construcción de un ethos del trabajo, justamente para evitar que el sujeto termine reificado e instrumentalizado.

La acción constituye el vínculo específico que hace "humanidad" a las personas y sus relaciones. Trasciende la necesidad y la racionalidad instrumental. Se vincula con la posibilidad de ser comunitariamente despojados de dinamismos manipuladores y egoístas. "La acción se acerca al sentido aristotélico de praxis, es decir, a un acto que tiene su fin en sí mismo, independiente de su utilidad" Para Arendt, "Con palabra y acto nos insertamos en el mundo humano y esta inserción es como un segundo nacimiento, en el que confirmamos y asumimos el hecho desnudo de nuestra original apariencia física" (Arendt, citado por, Barone y Mella, 2017, p. 203). Natalidad como renovación, como espacio para hacernos un lugar en la sociedad, para identificarnos.

Natalidad es el término que utiliza Arendt para referirse a la capacidad humana de renovación, que se lleva a cabo continuamente a través de la recepción de los recién llegados y el gusto por compartir con ellos la esfera pública. [...] Para Arendt la misión de la educación es conservar ante todo esta natalidad. (Barone y Mella, 2017, p. 204) La natalidad reconoce la provisionalidad del sujeto, la fragilidad de los vínculos, la imprevisibilidad del ser humano. Reconocer estos matices permite una escena más pertinente y compleja: la escucha al otro por la latente novedad, la renovación de vínculos por la fragilidad, la comprensión del sufrimiento como estado propio y casi obligado de la humanidad6.

Puede inferirse, que una educación contable comprometida con la transformación del sujeto en un ser que "sabe", que es emocional, que actúa política y estéticamente, puede promoverse si se comprende la educación como acción, para la acción. Es una educación contable, como dice Arendt, formulada para preservar la natalidad y para construir y compartir colectivamente la esfera pública. Mucho más necesario en contabilidad, que es un saber permeado por la lógica del mercado y que legitima la instrumentalidad propia del modelo económico vigente al proveer imágenes sintéticas del mundo de las 
organizaciones (reduccionismo económico - financiero) y al contar con la confianza de la sociedad que asume como válida dicha imagen. Por ello la educación contable debe cimentarse en el doble propósito de armar a los contadores de elementos para que ellos sepan de sí, y de construir un lugar para comprender la contabilidad no como herramienta, sino como un potente artefacto social que puede tanto hacer el bien como el mal.

Esta visión de la educación - acción se complementa de forma muy sugerente con la noción de "cuidado de sí" estudiada por Foucault en diferentes etapas de la humanidad. En especial el sentido de tal expresión para el período helenístico. Cuidar de sí es, "un ejercicio de sí sobre sí por el cual uno intenta elaborarse, transformarse y acceder a un determinado modo de ser." (Foucault, 2017, p. 258) "será ocuparse de sí en cuanto uno es 'sujeto de' cierta cantidad de cosas: sujeto de acción instrumental, sujeto de relaciones con el otro, sujeto de comportamientos y actitudes en general, sujeto también de relación consigo mismo" (2018, p. 71). La educación debería propender por consolidar los espacios formativos que sean del caso para que el sujeto logre "identificarse", labrarse una imagen profundamente consciente y permitiendo que los otros cuenten con la posibilidad de construir su propio proyecto de vida. Si el otro no puede acceder a la confección de su imagen estética y política, es apenas lógico que se ponga en peligro el cuidado de sí, porque todos somos otros, en ese camino de identificarnos, y necesitamos de los otros para saber quiénes somos y poder actuar libremente; y para poder ser un colectivo meridianamente armónico.

Por ello este ocuparse de sí no puede ser relacionado con la forma del individualismo y egoísmo característicos, por ejemplo, de una sociedad bajo un modelo económico ultraliberal. El ocuparse de sí tiene una profunda relación con la libertad, y en Foucault la libertad es la condición ontológica de la ética.

[...] Pero la ética en el sentido como los griegos podían entender el ethos, era la manera de ser y la manera de conducirse. Era un modo de ser sujeto y en cierto modo de hacer, visible para los otros. El ethos era la manera de cada uno de traducirse por su vestimenta, por su paso, por su modo de andar, por la calma con la cual él respondía a todos los sucesos, etc. [...] Pero para que esta práctica de la libertad tome forma de un ethos que sea bueno, bello, honorable, estimable, memorable, y que pueda servir de ejemplo, hace falta todo un trabajo de sí sobre sí. [...] Para los griegos, no porque sea cuidado de los otros es ético. El cuidado de sí es ético en sí mismo; pero implica relaciones complejas 
con los otros, en la medida, que ese ethos de la libertad es también una manera de cuidar de los otros. (Foucault, 2018, p. 263)

¿Y cómo se configura esta ética, del cuidado de sí y de los otros y esta forma de la vida del hombre como acción y natalidad? Varios serían los lugares, pero, resulta evidente que la educación es un espacio privilegiado y obligatorio. Y al hablar de educación contable la tarea estriba en contar con una institucionalidad que trascienda las lógicas mercantiles (tener estudiantes - clientes y maximizar el margen de contribución del proceso educativo), contar con un profesorado comprometido y reflexivo sobre su papel y dispuesto a dejarse conmover por nuevas formas de la pedagogía y la didáctica, sobre todo, dispuestos a recibir una cariñosa bofetada para que despierten de sus certezas y comprendan el profundo impacto que tienen en la construcción de identidades en sus estudiantes;

(...) en lo sucesivo, el maestro ya no es el maestro de la memoria. Ya no es aquel que, al saber lo que el otro no sabe, se lo transmite. Ni siquiera es quien, al saber que el otro no sabe, sabe mostrarle que en realidad sabe lo que no sabe. El maestro ya no va a inscribirse en ese juego. En lo sucesivo, el maestro es un operador en la reforma del individuo y su formación como sujeto. Es el mediador en la relación del individuo con su construcción de sujeto. (Foucault, 2018, p. 133)

Y también la educación contable deberá comprometerse con identificar el sentido de La Contabilidad, preguntándose de qué está hecha y cómo operativizarla, pero también de cómo es que llegó a ser lo que es, bajo qué relacionamientos socio - históricos, qué impactos genera en las relaciones sociales y qué otra contabilidad es posible.

Estas coordenadas implican transformar el marco de necesidades que endilgamos a la educación contable. No se trata del empleo, de ascenso social, del mercado, de hacer parte de la tecnoestructura corporativa, del lenguaje común de los negocios globales, de las competencias laborales, de la audacia y el pragmatismo, de la racionalidad optimizadora, del emprenderismo, de la globalización de la economía, de liderazgos manageriales, del desgastante trabajo en la gran firma, entre otros. Se trataría más bien de reconocer que los sujetos, en este caso los Contadores Públicos, requieren otras posibilidades; necesitan, a más de la epistemología, tecnología y socio - crítica contables, desarrollar otros valores:

Valores humanos básicos (Grisez, Boyle, y Finnis) * Vida (salud, reproducción, seguridad),

* Conocimiento y experiencia estética, 
* Trabajo y juego significativo (excelencia),

* Amistad: relaciones y amistades,

* Autointegración: armonía, integridad o paz interior,

* Autoexpresión o razonabilidad práctica (tomar decisiones en paz),

* Trascendencia (armonía con fuentes de sentido sobrehumanas, teístas o no).

9 requerimientos de razonabilidad práctica; (Finnis)

* Un plan de vida coherente,

* No existir preferencias arbitrarias entre los valores básicos, * No existir preferencias arbitrarias entre personas,

* Sentido apropiado del desprendimiento,

* Sentido apropiado del compromiso,

* Medios eficientes,

* En toda acción respeto por cada valor básico,

* Búsqueda del bien común de la propia comunidad,

* Seguir la conciencia. (Barone y Mella, 2018, p. 197 - 198)

Sin embargo, estos valores y requerimientos de razonabilidad práctica, pueden ser promovidos si se insertan en el marco de una comprensión profunda de la condición humana y siempre que la teleología educativa propenda por el cuidado de sí y la natalidad. Y lo característico de la condición humana es "la radical imprevisibilidad de las decisiones personales, la apertura respetuosa al misterio único de cada persona y el enraizamiento del individuo en su condición mundanal, elementos fundamentales para pensar la educación.” (Barone y Mella, 2018, p. 198).

Si entendemos la acción educativa como la construcción del relato de una vida (Bárcena y Mélich, 2020), hará falta para este propósito formarse en capacidad para la autocrítica. "Sólo a través del descubrimiento de la capacidad simbólica del ser humano, la acción educativa puede ofrecer resistencia a la presión anónima del conocimiento científico y tecnológico, así como oponerse a la lógica tiránica e imperativa de la razón instrumental” (p. 83). En palabras de Foucault y en su comprensión de la modernidad,

\section{Conclusiones}

Este devenir por los testimonios de algunos de nosotros (profesores y directores de programa de Contaduría Pública) más la tensión por encontrar lugares teóricos desde los cuales mejorar la observación y potenciar la acción, nos instala en la necesaria invitación a la comunidad académica de la contabilidad para identificar rutas de movilidad y conmoción para favorecer la educación contable. 
Con todo, las derivas de esta construcción están sujetas a revisión. Hemos identificado en las descripciones de los actores encuestados un panorama que podemos resumir como problemático. Varias universidades presentan problemas en la estructuración y reflexión sobre lo pedagógico. Algunos testimonios señalan que persiste una orientación pedagógica tradicional y conductista. Los planes de estudio están construidos de forma agregada y es visible la ausencia de núcleos integradores. En algunos casos se describen propuestas más novedosas que deben ser auscultadas en sus potencialidades.

Persiste en nuestros currículos una dosis importante de inflexibilidad. Es probable que en algunos casos existan dinámicas para actualizar contenidos, pero la posibilidad de brindar rutas de formación de libre escogencia por parte del estudiante es escasa. Del mismo modo, existe una tendencia a concebir la formación integral supeditada del ofrecimiento de asignaturas electivas, humanísticas o cursos de ética. En otros casos la posibilidad de actividades extracurriculares que brinda la universidad suple esta necesidad.

Se hace palmaria la ausencia de un trabajo más fortalecido en la formación en el campo de la fundamentación contable desde áreas como la epistemología y la teoría contable. Por otro lado resulta cuestionable, o en algún sentido curioso, que se estén desarrollando procesos de investigación en contabilidad, y persista una resistencia por la caracterización disciplinal, histórica y científica de la contabilidad.

La comunicación de los programas de Contaduría Pública con las necesidades del medio, en el ámbito organizacional y comunitario, resulta débil por no decir nula. En algunos casos se plantea que los consultorios contables, los trabajaos de grado y la extensión universitaria suplen esta función. Nosotros creemos que es procedente investigar sobre las dinámicas de esta relación para poder hacer una valoración más completa del principio curricular de pertinencia.

La gestión curricular de programas de Contaduría Pública, puede estar soslayando funciones académicas en privilegio de aspectos administrativos y financieros. Entendemos que esta situación se produce en el ámbito de la tensión entre la producción de conocimiento y formación profesional idónea, con la rentabilización de la educación en la perspectiva de negocio.

Tal como fue señalado, intervenir estos tópicos aisladamente y sin un referente poderoso sobre el sentido de la educación contable, resultaría poco efectivo. El esnobismo creciente en los programas para presentarse con otra cara ante los procesos de acreditación y registro, no genera un impacto en la cotidianidad de la educación y por ende no afecta la formación del estudiante. El exceso de retórica consignada en los documentos que 
presentan los programas deja un sinsabor cuando son contrastados con la vida académica de los profesores, los administradores y los estudiantes. La instrumentalización, la cosificación, y el rentismo son valores socorridos, quizá no en forma autodeclarada pero evidente, para dibujar el ambiente de la educación contable colombiana.

Esta educación debería comprometerse con un proceso de transformación radical. Y esa transformación debe tomar un punto de partida en el que se resuelvan interrogantes como ¿para cuál sociedad educamos? ¿qué sociedad queremos? ¿para qué hombres y mujeres educamos? ¿qué hombres y mujeres contadores queremos? ¿cuál concepción de la educación nos permite desarrollar esta deontología?

Creemos que la educación como acción y para la acción es un lugar donde se privilegia el reconocimiento de los vericuetos de la condición humana, su incertidumbre y su fragilidad, donde se reconoce la condición de natalidad del que se educa, su posibilidad en el terreno para crear un relato de sí de forma consciente. Una educación que entiende el trabajo como artificio necesario pero no como el núcleo del proyecto formativo de contadores públicos. Una educación contable que hace todo lo posible para que el estudiante aprenda a cuidar de sí y de los otros construyendo una imagen ética, estética y política, para que configure un ethos de la libertad y que por lo tanto logre desprenderse adecuadamente de procesos de instrumentalización, cosificación y ninguneo de la condición de humanidad. Una educación que comprenda la contabilidad como el saber estratégico que es, y que les muestre a los estudiantes los impactos que tiene en la configuración de la subjetividad y en la legitimación de ciertas relaciones sociales.

Si asuntos como estos son clarificados, son consensuados, y los profesores se dan cuenta de la profunda reforma que implican, estaremos preparados para iniciar transformaciones educativas que ya no resulten paliativos aislados, sino verdaderos giros en la escena de la formación de contadores públicos.

\section{Bibliografia}

Arendt, H. (2019). Entre el pasado y el futuro. Ocho ejercicios sobre la reflexión política. Cap. V. La crisis de la educación. (185-208). Barcelona: Península

Ariza, D., \& Soler, M. (2020). La crisis de la Universidad. ¿Una lección para reconstruir el tránsito disciplinar de la Contabilidad en Colombia? LUMINA 5 , 171-194.

Bárcena, F. y Mélich, J. (2020). La educación como acontecimiento ético, natalidad, narración y hospitalidad. (63-90) España: Paidós 
Barone, S., \& Mella, P. (2017). Acción educativa y desarrollo humano en la universidad de hoy. Revista Iberamericana de Educación, 31 , 187-219.

Barragán, D. (2018). Curriculum e interacciones en el aula. La formación en Contaduría Pública. En Perspectivas Críticas de la Contabilidad - VII Simposio Nacional de Investigación Contable y Docencia (págs. 159-172). Bogotá D.C.: Universidad Nacional de Colombia.

Díaz, A., \& Quiroz, R. (2021). Corrientes pedagógicas, modelos pedagógicos y enfoques curriculares. Relación sistemática entre ellos. Revista avanzada, 10 , 116-129.

Elizalde, A. (2021). Hacia una Universidad extendida. Revista On-line de la Universidad Bolivariana , 1-8. Florez, R., Díaz, O., Tobón, A., \& Agudelo, G. (2002). Factores asociados a la calidad de la docencia universitaria. Serie Calidad de la Eduación Superior, 6. Colombia: Ministerio de Educación Nacional.

Foucault, M. (2017). La hermenéutica del sujeto. Argentina: Fondo de cultura económica. Foucault, M. (2017). La ética del cuidado de sí como práctica de la libertad. Nombres, Revista de filosofía, 15 , 257-280.

Foucault M. (2018). ¿Qué es la Ilustración? Actual, 28.

Gómez, M., \& Ospina, C. (2019). Avances interdisciplinarios para una comprensión crítica de la Contabilidad: Textos paradigmáticos de las corrientes heterodoxas. Medellín: Universidad Nacional; Universidad de Antioquia.

González, E. (2019). Corrientes pedagógicas contemporáneas. Medellín: Universidad de Antioquia - Facultad de Educación.

Gracia, E. (2017). Sobre las prácticas de gestión en la Universidad. LUMINA, 07, 110128.

Gutiérrez, L., \& Denis, L. (2020). La etnografía en la visión cualitativa de la educación. Cuadernos de filosofía Latinoamericana, 86-87, 212-237.

ICFES - FIDESC. (2020). La Contaduría Pública del nuevo milenio. Renovación curricular. Bogotá: ECOE Ediciones.

López, F. (2017). Posibles escenarios mundiales de la educación superior. Perfiles educativos, 109, (27), 140-165.

Martínez, G. (2018). La educación contable: encrucijada de una formación monodisciplinaria en un entorno complejo e incierto. Popayán: Universidad del Cauca.

Ospina, C. (2017). Las tramas de la Contabilidad: trazos para quienes empiezan su formación en Contaduría Pública. Contaduría Universidad de Antioquia, 48, 155 186. 
Ospina, C. (2018). Sobre la investigación en contabilidad. Algunos apuntes. Contaduría Universidad de Antioquia, 46, 73-110.

Quijano, O., Gracia, E., Martínez, G., Ariza, D., \& Rojas, W. (2020). Del hacer al saber. Realidades y perspectivas de la educación contable en Colombia. Popayán: Universidad del Cauca - CCINCO. Rojas, W. (2018). Congoja por una educación contable fútil. Contaduría Universidad de Antioquia, 52,259 - 274

Túa, J. (2018). Globalización y regulación contable. Algunos retos para nuestra profesión en América Latina. En Ensayos sobre contabilidad y economía. En homenaje al profesor Ángel Saez Torrecilla. Tomo I (págs. 855-908). Madrid: ICAC.

Vargas, G. (2020). La educación del futuro como futuro de la educación: ensayo fenomenológico de filosofía de la educación. pedagogía y saberes, 14, 57-66. 